\title{
Heat-cured acrylic resin reinforcement with aluminum oxide: Degree of conversion, monomer release and flexural strength
}

\author{
Ibrahim M Hamouda ${ }^{1,2 *}$ and Alaa Makke ${ }^{3}$ \\ ${ }^{1}$ Professor of Dental Biomaterials, Faculty of Dentistry, Umm Alqurra University, Makkah, KSA \\ ${ }^{2}$ Professor of Dental Biomaterials, Faculty of Dentistry, Mansoura University, Egypt \\ ${ }^{3}$ Assistant Professor of Oral and Maxillo-Facial Surgery, Faculty of Dentistry, Umm Alqurra University, Makkah, KSA
}

\begin{abstract}
Background: Degree of monomer conversion during processing of acrylic resin denture base materials is very critical in determination of monomer release and mechanical properties of acrylic resin in service.

Objectives: The purpose of this research project was to investigate the effect of aluminum oxide powder reinforcement on the degree of monomer conversion, residual monomer, deflection at fracture and flexural strength after processing of heat-cured acrylic resin denture base materials. Also, the correlation between these properties was statistically tested.

Materials and methods: The materials used were conventional heat-cured and aluminum oxide powder-reinforced acrylic resin denture base materials $(2.5 \%$ and $5 \%$ aluminum powder). Samples were prepared according to the manufacturer's instructions, ADA Specifications no. 12 and the International Organization for Standardization Recommendation. Acrylic resin samples of specific dimensions were prepared from unreinforced and reinforced acrylic resin materials using stainless steel plates. The degree of conversion was determined using FTIR Spectrometer. The concentrations of released methyl methacrylate monomer was measured using isocratic high-performance liquid chromatography. Flexural strength was tested using three point-bending test with a universal testing machine.

Results: Aluminum oxide powder reinforcement showed slight increased degree of conversion than that of the unreinforced denture base resins. The released monomer in deionized water from the reinforced acrylic resins was significantly lower than that of the unreinforced specimens. The deflection at fracture of the reinforced specimens was significantly lower than that of the unreinforced acrylic resin. The flexural strength was significantly increased by addition of $2.5 \%$ and $5 \%$ aluminum oxide powder when compared to the unreinforced group. There was high positive correlation between the degree of conversion and flexural strength. On the other hand, there was negative correlation between degree of conversion and monomer release.
\end{abstract}

Conclusions: Aluminum oxide powder reinforcement was slightly increased the degree of conversion of the heat-cured acrylic resin. Aluminum oxide powder reinforcement was significantly reduced the amount of monomer released and the deflection at fracture heat-cured specimens. The reinforced specimens showed significantly increased flexural strength than that of the unreinforced specimens. There was high positive correlation between the degree of conversion and flexural strength. There was negative correlation between degree of conversion and monomer release.

\section{Introduction}

Conventional heat-activated acrylic resin denture base materials are still the most commonly used denture base materials. Curing of the acrylic dough mix in the curing bath may affect the polymerization of the denture base resin material. The degree of conversion of the acrylic resin monomer is a measure of carbon-carbon double bonds $(c=c)$ converted into carbon-carbon single bonds $(c-c)$. As the temperature increases, the molecular mobility increases, leading to increased monomer polymerization. Polymerization of heat-cured acrylic resin by heat depends on time and temperature. Various amounts of unreacted methyl methacrylate monomer remain after curing of the denture bases [1].

The conversion of monomer to polymer may not be complete and a residual monomer is left in the polymeric material; this will affects the properties of the acrylic resin denture base materials [2]. Highperformance liquid chromatography coupled to an ultra-violet detector method was used to monitor the elution profile of methyl methacrylate monomer from poly (methyl methacrylate) resin produced by various polymerization modes. The un-polymerized methyl methacrylate monomer continued to leach out in the distilled water throughout the five-week period after curing [3].

A simple HPLC-UV method was used for measuring the elution of methyl methacrylate and methacrylic acid monomers from poly (methyl methacrylate) resin. The leached amount into the artificial saliva from the resins was much higher, compared to that into water

${ }^{\star}$ Correspondence to: Ibrahim M. Hamouda, Professor of Dental Biomaterials, Faculty of Dentistry, Umm Alqurra University, Makkah, KSA; Professor of Dental Biomaterials, Faculty of Dentistry, Mansoura University, Egypt, E-mail: imh100@hotmail.com

Key words: aluminum oxide powder, reinforcement, acrylic resin, degree of conversion, flexural strength, monomer release

Received: July 15, 2020; Accepted: August 03, 2020; Published: August 07, 2020 
[4]. Residual monomer may diffuse from acrylic resin denture bases causing irritation or allergic reactions to the supporting tissues. Correct curing methods reduce residual monomer content in the denture bases. Correct curing cycles keep the residual monomer in the range of 1-3\% that is well tolerated by vital tissues [5].

The acceptable curing method for acrylic polymerization is that capable to achieve the best properties of the acrylic resin denture bases, e.g. fracture toughness, static strength, flexural modulus and monomer release. It has been shown that high levels of residual monomer adversely affect acrylic resin properties like hardness \& porosity [6,7]. One of the properties of acrylates is monomer release, which cause dimensional changes, thereby subjecting the material to internal stresses that may result in crack formation and fracture of the denture during service $[8,9]$.

The acrylic resin denture base materials showed low strength, soft and fairly flexible, brittle on impact, and fairly resistant to fatigue. In evaluation of denture plastics, transverse strength measurements are used to a greater extent than either tensile or compressive strength, because this test more closely represents the type of loading in vivo. The geometry of denture bases is complex, so, the stresses can be concentrated in flaws on the surface of the denture base or in the frenum notches. The concentrated stresses lead to cracks in the denture base. The brittle nature of acrylic resin under its glass transition temperature ( $\mathrm{Tg}$ ) and its susceptibility to cyclic loading, fatigue fracture of dentures is a common clinical manifestation [5].

Conventional methods employed to reinforce a denture base polymers generally involve the use of metal wires or plates, fibers, metal powder or rubber toughening. To overcome the problem of denture fractures by improving the mechanical properties of the denture base polymer. The types of fibers that have been used to reinforce denture base polymers include aramide fibers, carbon/graphite fibers, ultrahigh molecular weight polyethelene fibers and glass fibers [10].

This study was concerned with the reinforcing of the conventional heat-cured acrylic resin powder with $2.5 \%$ and $5 \%$ of aluminum oxide powder to test the reinforcing effects on degree of monomer conversion, monomer release, flexural strength and their correlations.

\section{Materials and methods}

The materials used in this study were, conventional heat-cured acrylic resin denture base material, Major base 20 (Major Prodotti Dentari S.p.A; Italy), Aluminum oxide powder (NEN TECH LTD, fin at. W. 26.98 min 99.6\%), polyvinyl siloxane impression material (Aquasil, Dentsply International Inc, York, PA, USA), Dental stone (Hydrocal Dental stone, Moldano, Bayer Lerekusen, Germany) and Baseplate wax (Tru Wax, Dentsply International Inc., York, Pa.).

\section{Testing the degree of monomer conversion}

30 acrylic resin samples were prepared from the unreinforced, 2.5 $\%$ aluminum reinforced and 5\% aluminum reinforced acrylic resin powder according to manufacturer's instructions and American Dental Association Specification \# 12 [11]. The specimens dimensions were, $50 \mathrm{~mm}$ length, $50 \mathrm{~mm}$ width and $1 \mathrm{~mm}$ thickness. Polyvinyl siloxane impressions were made using the putty form for the stainless steel plates. After setting of the impression, the impression molds were filled with melted baseplate wax and pressed using glass plate to obtain flat and smooth wax specimens. After hardening of the wax specimens, they were removed from the impressions and divided randomly into three groups, 10 samples each as follow:
Group 1. Prepared from unmodified conventional heat-cured acrylic resin powder.

Group 2. Prepared from $2.5 \%$ aluminum oxide powder modified heat-cured acrylic resin.

Group 3. Prepared from modified acrylic resin powder with $5 \%$ aluminum oxide powder.

The wax samples were flasked in dental stone using the compression molding technique [12]. Washing was done for the wax specimens for 10 minutes in boiling water and sodium alginate separating medium was applied to cleaned stone molds. The acrylic resin powder / liquid ratio was mixed and then packed in the dough stage, packed in the denture flasks and pressed. The flasked specimens were immersed in water bath at room temperature in a thermostatically controlled unit. The temperature was raised slowly to $73 \pm 1^{\circ} \mathrm{C}$ for 90 minutes, and then elevated to the boiling point at $100^{\circ} \mathrm{C}$ for 30 minutes. Bench cooling was done for the flasks before opening [5]. The cured acrylic resin plates were carefully removed from their molds and finished using a polishing machine with wet silicon carbide paper disk 600 grit size.

Each specimens was prepared for analysis with FTIR Spectrometer (FTIR-820 Ipc, Shimatzu) to determine the degree of monomer conversion. The aliphatic carbon-to-carbon double bonds $(\mathrm{C}=\mathrm{C})$ concentration of the uncured material was calculated at $1636 \mathrm{Cm}$ ${ }^{1}$. A thin slice of the cured material was used to determine the concentration of the aliphatic $\mathrm{C}=\mathrm{C}$ using the FTIR Spectrometer. The percent of monomer-to-polymer is calculated in the cured specimens in relationship to the total $\mathrm{C}=\mathrm{C}$ available in the uncured materials [1].

Resin cure was calculated by determining the proportion of weight percent methacrylate group (WPMG) available after curing (C) compared to the amount present in the uncured $(\mathrm{U})$ solution using the following formula $[1,13]$ :

Percent degree of conversion $=\left(1-\mathrm{WPMG}_{\mathrm{C}} / \mathrm{WPMG}_{\mathrm{U}}\right) \times 100 \%$

Where $W P M G_{C}$ is the weight percent methacrylate groups in cured resin and $\mathrm{WPMG}_{\mathrm{U}}$ is the weight percent methacrylate groups in uncured resin.

\section{Testing of the released monomer}

30 disc-shaped samples were prepared from the unreinforced and reinforced heat-cured acrylic resin powders, 10 samples each. The specimens dimensions is $50 \mathrm{~mm}$ in diameter and $3 \mathrm{~mm}$ thickness. All specimens were tested for monomer release according to the ISO 1567:2000. Each sample was stored in $10 \mathrm{ml}$ of deionized water in a sealed container in dark conditions at $37^{\circ} \mathrm{C}$ for 7 days. The specimens were removed after storage period, and the amount of methyl methacrylate monomer was determined in the water after three extractions with 0.6 $\mathrm{ml}$ of $\mathrm{n}$-hexane (Merck, Darmstadt, Germany). The final volume of extract was adjusted to $2.0 \mathrm{ml}$ with $\mathrm{n}$-hexane. The concentrations of released methyl methacrylate monomer was measured using isocratic high-performance liquid chromatography (HPLC; Waters, Milford, MA) with a reverse-phase column (LiChroCART 250-4 Cartridge, LiChrospher 100 RP-8 $(\mu \mathrm{m})$ column, Merck. Acetonitrile (HPLC grade, Merck) with water (50:50) was the mobile phase; the flow rate was $1 \mathrm{ml} /$ $\mathrm{min}^{-1}$, with detection at $254 \mathrm{~nm}$. The peak area of methyl methacrylate monomer was calculated on the HPLC trace. Each specimens was measured three times. The amount of leached MMA was determined using a standard calibration curve with MMA concentrations of $1,5,10,100,500 \& 1000$ p.p.m. as controls [14,15]. 


\section{Testing of the flexural strength}

30 samples were prepared from the unreinforced and reinforced heat-cured acrylic resin powders, 10 samples each. The transverse strength specimens dimensions were, $65 \mathrm{~mm}$ length, $10 \mathrm{~mm}$ width and $2.5 \mathrm{~mm}$ thickness. Specimens were stored in distilled water at room temperature for 24 hours. Flexural strength was tested using three point-bending test with a universal testing machine (Lloyd, type 500, England) with a cross head speed of $2 \mathrm{~mm} / \mathrm{min}$ until fracture. The load was applied at the center of the specimen. The machine is computerized to calculate the flexural strength from the applied load and the deflection at fracture from the introduced data to the testing machine.

\section{Statistical analysis}

The tabulated data were exposed to one way ANOVA test to detect the significant difference among the tested materials. The test with ANOVA significance was exposed to LSD test to detect the significant difference between groups at $\mathrm{p} \leq 0.05$.

\section{Results}

Means and standard deviations of percent monomer conversion of unreinforced and aluminum oxide reinforced heat-cured acrylic resins are presented in (Table 1). One-way ANOVA test showed no significant difference among the tested groups $(P \geq 0.05)$. Aluminum oxide reinforced groups showed insignificant increased degree of monomer conversion than that of the unreinforced group.

Means and standard deviations of monomer released (ppm) of unreinforced and aluminum oxide reinforced heat-cured acrylic resins are presented in (Table 2). One-way ANOVA test showed significant difference among the tested groups $(\mathrm{P} \leq 0.05)$. The statistical analysis of the results indicated that there were significant differences between the unreinforced and aluminum oxide reinforced groups. 5\% aluminum reinforced group showed significantly lower monomer release than that of the unreinforced and $2.5 \%$ aluminum oxide reinforced group. Also, $2.5 \%$ aluminum reinforcement significantly reduced the released monomer when compared to the unreinforced heat-cured acrylic resin.

Means and standard deviations of specimen's deflection( $\mathrm{mm}$ ) at fracture of unreinforced and aluminum oxide reinforced heat-cured acrylic resins are presented in (Table 3). One-way ANOVA test showed significant difference among the tested groups $(\mathrm{P} \leq 0.05)$. The statistical analysis of the results indicated that there were significant differences between the unreinforced and aluminum oxide reinforced groups. 2.5 $\%$ and $5 \%$ aluminum reinforcement were significantly reduced the deflection at fracture of the heat-cured acrylic resin.

Means and standard deviations of flexural strength (Mpa) of unreinforced and aluminum oxide reinforced heat-cured acrylic resins are presented in (Table 4). One-way ANOVA test showed significant difference among the tested groups $(\mathrm{P} \leq 0.05)$. The statistical analysis of the results indicated that $2.5 \%$ and $5 \%$ by weight of aluminum oxide powder reinforcement were significantly increased the flexural strength of the heat-cured acrylic resin $(\mathrm{P} \leq 0.05)$. There was high positive correlation between the degree of conversion and flexural strength. There was negative correlation between degree of conversion and monomer release (Table 5).
Table 1. Means and standard deviations of monomer conversion percent of unreinforced and aluminum oxide reinforced heat-cured acrylic resins

\begin{tabular}{|c|c|c|c|}
\hline $\begin{array}{c}\text { Types of acrylic } \\
\text { resins }\end{array}$ & $\begin{array}{c}\text { Conventional } \\
\text { unreinforced acrylic } \\
\text { resin }\end{array}$ & $\begin{array}{c}\mathbf{2 . 5 \%} \text { aluminum } \\
\text { reinforced acrylic } \\
\text { resin }\end{array}$ & $\begin{array}{c}\mathbf{5 \%} \text { aluminum } \\
\text { reinforced acrylic } \\
\text { resin }\end{array}$ \\
\hline Mean \pm SD & $94.8 \pm 5.9$ & $95.2 \pm 4.7$ & $95.8 \pm 6.9$ \\
\hline F-value & & 9.7 & \\
\hline P-value & & $0.95^{+}$ \\
\hline
\end{tabular}

$+\mathrm{p} \geq 0.05=$ no significant difference.

Table 2. Means and standard deviations of monomer release(ppm) of unreinforced and aluminum oxide reinforced heat-cured acrylic resins

\begin{tabular}{|c|c|c|c|}
\hline $\begin{array}{l}\text { Types of acrylic } \\
\text { resins }\end{array}$ & $\begin{array}{c}\text { Conventional } \\
\begin{array}{c}\text { unreinforced acrylic } \\
\text { resin }\end{array}\end{array}$ & $\begin{array}{l}2.5 \% \text { aluminum } \\
\text { reinforced acrylic } \\
\text { resin }\end{array}$ & $\begin{array}{l}5 \% \text { aluminum } \\
\text { reinforced acrylic } \\
\text { resin }\end{array}$ \\
\hline Mean \pm SD & $6.9^{(\mathrm{A})} \pm 0.9$ & $5.2^{(\mathrm{B})} \pm 0.7$ & $4.3^{(\mathrm{C})} \pm 0.8$ \\
\hline F-value & \multicolumn{3}{|c|}{13.9} \\
\hline P-value & \multicolumn{3}{|c|}{$0.01^{*}$} \\
\hline LSD & \multicolumn{3}{|c|}{1.9} \\
\hline
\end{tabular}

$* \mathrm{p} \leq 0.01=$ significant difference.

Means with different superscripted letters are significantly different.

Table 3. Means and standard deviations of specimen's deflection at fracture of unreinforced and aluminum reinforced heat-cured acrylic resins $(\mathrm{mm})$

\begin{tabular}{|c|c|c|c|}
\hline $\begin{array}{c}\text { Types of acrylic } \\
\text { resins }\end{array}$ & $\begin{array}{c}\text { Conventional } \\
\text { unreinforced acrylic } \\
\text { resin }\end{array}$ & $\begin{array}{c}\mathbf{2 . 5 \%} \text { aluminum } \\
\text { reinforced acrylic } \\
\text { resin }\end{array}$ & $\begin{array}{c}\mathbf{5 \%} \text { aluminum } \\
\text { reinforced acrylic } \\
\text { resin }\end{array}$ \\
\hline Mean \pm SD & $4.9^{(\mathrm{A})} \pm 0.7$ & $2.7^{(\mathrm{B})} \pm 0.3$ & $2.5^{(\mathrm{C})} \pm 0.4$ \\
\hline F-value & & 2.5 & \\
\hline P-value & & $0.05^{*}$ \\
\hline LSD & & 1.1 \\
\hline
\end{tabular}

$* \mathrm{p} \leq 0.05=$ significant difference

Means with different superscripted letters are significantly different.

Table 4. Means and standard deviations of flexural strength (Mpa) of unreinforced and aluminum reinforced heat-cured acrylic resins

\begin{tabular}{|c|c|c|c|}
\hline $\begin{array}{c}\text { Types of acrylic } \\
\text { resins }\end{array}$ & $\begin{array}{c}\text { Conventional } \\
\text { unreinforced acrylic } \\
\text { resin }\end{array}$ & $\begin{array}{c}\mathbf{2 . 5 \%} \text { aluminum } \\
\text { reinforced acrylic } \\
\text { resin }\end{array}$ & $\begin{array}{c}\mathbf{5 \%} \text { aluminum } \\
\text { reinforced acrylic } \\
\text { resin }\end{array}$ \\
\hline Mean \pm SD & $115.9^{(\mathrm{A})} \pm 13.5$ & $125.3^{(\mathrm{B})} \pm 12.8$ & $133.4^{(\mathrm{C})} \pm 13.9$ \\
\hline F-value & & 4.5 & \\
\hline P-value & & $0.05^{*}$ & \\
\hline LSD & & 14.8 \\
\hline
\end{tabular}

$* \mathrm{p} \leq 0.05=$ significant difference.

Means with different superscripted letters are significantly different.

Table 5. Correlations between the degree of conversion, monomer release, deflection at fracture and flexural strength of heat-cured specimens

\begin{tabular}{|c|c|c|c|c|}
\hline Correlations & $\begin{array}{c}\text { Degree of } \\
\text { Conversion }\end{array}$ & $\begin{array}{c}\text { Monomer } \\
\text { release }\end{array}$ & $\begin{array}{c}\text { Deflection at } \\
\text { fracture }\end{array}$ & $\begin{array}{c}\text { Flexural } \\
\text { strength }\end{array}$ \\
\hline $\begin{array}{c}\text { Degree of } \\
\text { Conversion }\end{array}$ & 1 & $-0.759^{*}(0.004)$ & $0.2(0.2)$ & $0.4^{* *}(0.004)$ \\
\hline $\begin{array}{c}\text { Monomer } \\
\text { release }\end{array}$ & --------- & 1 & $0.03(0.2)$ & $0.02(0.2)$ \\
\hline $\begin{array}{c}\text { Deflection at } \\
\text { fracture }\end{array}$ & -------------- & ------------ & 1 & $0.008(0.959)$ \\
\hline Flexural strength & ---------- & --------- & ---------- & 1 \\
\hline
\end{tabular}

Correlation is significant at the 0.01 level (2-tailed).

** High positive correlations.

- * High negative correlations. 


\section{Discussion}

Conventional heat-cured acrylic resins are still the predominant denture base materials in use. In the mouth, properties and functional efficiency of applied acrylic resins depend on internal factors related to the methods and conditions of polymerization and on external factors that are related to the environment in which the material is placed [16]. Efforts must be made to improve the handling properties, transverse deflection, and water sorption of radiopaque denture base materials. These materials has low strength, soft and fairly flexible, brittle on impact, and fairly resistant to fatigue failure [17].

Heat-cured acrylic resin composed mainly from Methyl methacrylate monomer that polymerized by activation of the monomer by heat to form poly Methyl methacrylate polymer [17]. Polymerization is followed by conversion of methyl methacrylate (MMA) to PMMA. During polymerization reaction of acrylic resins, not all the monomers are converted into polymers, and therefore some unreacted monomers called residual monomers are left [16].

The residual monomer content of a properly processed denture is less than $1 \%$. Irritation is slightly more common and is related to residual monomer. Irritation reactions are relatively rare and the reactions to the residual monomer should occur shortly after prosthesis delivery. As previously noted, the amount of residual monomer in processed polymethyl methacrylate is extremely low [18].

In the evaluation of denture plastics, flexural strength measurements are used to a greater extent than either tensile or compressive strength, because this test more closely represents the type of loading in vivo. Flexural strength is determined by applying an increasing load until fracture at the center of a test specimen. Flexural strength is therefore a combination of tensile and compressive strength and includes some of the elements of proportional limit and elastic modulus. A transverse deflection test has been used to evaluate denture base resins [17].

The results of the present research paper showed slight increase of degree of conversion of aluminum oxide reinforced heat-cured acrylic resins. This may be due to the aluminum powder is a good conductor material that help rising of temperature within the acrylic dough during polymerization. Polymerization of PMMA by heat may be affected by a variety of time and temperature parameters. The conversion of monomers to polymers is not complete, and some unreacted monomers, namely residual monomers, are left in the PMMA. Residual monomer is a well-known plasticizer and affects the physical and mechanical properties of acrylic resins. Also, residual monomer diffused from acrylic resin has been implicated as a primary irritant and a sensitizer that can cause an allergic eczematous reaction on both the skin and the oral mucosa [19].

The released monomer of aluminum oxide reinforced heat-cured acrylic resins was less than that of the conventional unreinforced group. This may be due to increasing the degree of monomer conversion in the present study. Polymerization time and temperature affect the residual monomer content, which is usually higher in autopolymerizing than in heat-polymerizing acrylic resins [20]. It has been stated that there is an inverse relationship between the degree of conversion and the residual monomer content, thus the higher the former the lower the latter [21].

The present study indicated that the deflection at fracture was decreased by addition of aluminum oxide powder. This may be attributed to the reduced amount of the residual monomer and the increased degree of monomer conversion to polymer. The excess residual monomer in the unreinforced group resulted in increased deflection of specimens at fracture because of the plasticizing effect [22].

However, acrylic resin denture base materials are brittle and have poor strength and thermal conductivity. Therefore, it is essential to improve the flexural strength of heat polymerized acrylic resin. A complete polymerization and better biological properties of heatpolymerized acrylates give them an advantage over the cold polymerized materials. Everyday work on improving the properties of dental resin materials contributes to a better quality [23].

It is notable that the addition of metal fillers provides improved strength, thermal conductivity and makes the material radiopaque [24]. The results of the present study are consistent with the findings of other researchers, who concluded that incorporation of $8 \%$ and $13 \%$ by weight of aluminum oxide powder to the heat-cured denture base resin significantly increased the flexural strength of the denture base resin, with the highest flexural strength observed in $13 \%$ by weight [25].

\section{Conclusions} drawn:

Within limitations of this work, the following conclusions were

1. Aluminum oxide powder reinforcement was slightly increased the degree of conversion of the heat-cured acrylic resin.

2. Aluminum oxide powder reinforcement was significantly reduced the amount of monomer released and the deflection at fracture heatcured acrylic resin.

3. The reinforced specimens showed significantly increased flexural strength than that of the unreinforced specimens of heat-cured acrylic resin.

\section{References}

1. Bartoloni JA, Murchison DF, Wofford DT, Sarkar NK (2000) Degree of conversion in denture base materials for varied polymerization techniques. J Oral Rehabil 27:488493.

2. Köroğlu A, Özdemir T, Pamir AD, Usanmaz A (2012) Residual acrylic monomer content of denture base resins with different fiber systems. J Appl Polym Sci 125(1).

3. Amin W (2007) Detection and Estimation of Monomeric Eluates from Poly (Methyl Methacrylate) Resin of Various Polymerisation Modes. Polymers and Polymer Composites 15(7):553-560.

4. Alawi MA, Amin W (2007) Effect of ageing on monomer elution from poly (methyl methacrylate) resin under simulated intra-oral conditions. Fresenius Environmental Bulletin 16(4):408-414.

5. Craig RG, Powers JM. Restorative Dental Materials, $11^{\text {th }}$ ed.Mosby, St Louis, Philadelphia. 2002; PP.639-658.

6. De Clerck JB (1987) Microwave polymerization of acrylic resins used in dental prosthesis. J Prosthet Dent 57:650-606.

7. Huggett R, Brooks S, Bastes JF (1985) Which curing cycle is best? Dent Technician Technology 38(suppl):11.

8. Woelfel JB (1971) Newer materials and techniques in prosthetic resin materials. Dent Clin North Am 15:67-79.

9. Vilaplana J, Romagura C, Comellana F (1994) Contact dermatitis and adverse oral mucosa membrane reactions related to the use of dental prostheses. Contact Dermatitis 30:80-84.

10. Narva KK, LassilaLV, Vallittu PK (2004) The static strength and modulus of fiber reinforced denture base polymer. Dent Mater 8:1-8

11. ADA Council on Dental materials and Devices (1975) Revised American Dental Association Specification No. 12 for denture base polymers. JADA 90:451-458.

12. Peixoto FA, Peixoto TB, Rached RN, Del Bell Cury AA (2002) Effect of intrinsic pigmentation on the flexural strength of a microwave-cured acrylic resin. Braz Dent $J$ 13:205-207. 
13. Rueggeberg FA (1994) Determination of rein cure using infrared analysis without an internal standard. Dent Mater 10:282.

14. ISO 1567. Dentistry Denture base polymers. Berlin: Beuth; 2000. 1567, $1^{\text {st }}$ Edition, June 1970 (ISO R 1567).

15. Shyh-Yuan 1, Yu-Lin L, Tzai-shin H (2002) Influence of polymerization conditions on monomer elution and micro hardness of auto polymerized polymethyl methacrylate resin. 110:179-183.

16. Celebi N, Yuzugullu B, Canay S, Yucel U (2008) Effect of polymerization methods on the residual monomer level of acrylic resin denture base polymers. Polymers for Advanced Technologies 19:201-206.

17. Craig RG, Powers JM. Restorative Dental Materials, $11^{\text {th }}$ ed.Mosby, St Louis, Philadelphia. 2002; PP.640-643.

18. Anusavice KJ, Shen C, Rawls HR. Phillips' Science of Dental Materials, $12^{\text {th }}$ ed., W.B. Saunders Co., Elsevier Inc. (USA), pp 495,496, 2013.

19. Vallittu PK, Ruyter IE, Buykuilmaz S (1998) Effect of polymerization temperature and time on the residual monomer content of denture base polymers. Eur J Oral SCi 106(1):588-593
20. Lee SY, Lai YL, Hsu TS (2002) Influence of polymerization conditions on monomer elution and microhardness of autopolymerized polymethyl methacrylate resin. European Journal of Oral Science 110(2):179-183.

21. Vallittu PK, Miettinen V, Alakuijala P (1995) Residual monomer content and its release into water from denture base materials. Dental Materials 11(6):338-342.

22. Nisar S, Moeen F, Hasan U (2015) Effect of varying curing regimes and powderliquid ratios on the flexural strength and surface porosities of heat cure acrylic: An invitro experiment. Int J Dent Sci Res 3:64-7.

23. Kostic M, Pejcic A, Igic M, Gligorijevic N (2017) Adverse reactions to denture resin materials. European Review for Medical and Pharmacological Sciences 21:5298-5305.

24. Ellakwa AE, Morsy MA, El-Sheikh AM (2008) Effect of aluminum oxide addition on the flexural strength and thermal diffusivity of heat-polymerized acrylic resin. $J$ Prosthodont 17(6):439-444.

25. Dagdiya M, Pakhan A, Bhoyar A, Godbole S, Sathe S (2019) Comparative Evaluation of the Flexural Strength of Heat Polymerized Acrylic Resin with the Addition of $8 \%$ and 13\% Aluminum Oxide Powder: An In-vitro Study. J Dent Mater Tech 8(2):65-72.

Copyright: $@ 2020$ Hamouda IM. This is an open-access article distributed under the terms of the Creative Commons Attribution License, which permits unrestricted use, distribution, and reproduction in any medium, provided the original author and source are credited. 